\title{
TECNOLOGIAS DIGITAIS NA FORMAÇÃO DOCENTE: RECONSTRUÇÃO DE SENTIDOS
}

\author{
Digital technologies in teaching training: \\ reconstruction of senses
}

\author{
Tecnologías digitales en la formación docente: \\ reconstrucción de sentidos
}

\begin{abstract}
RESUMO $O$ artigo reflete sobre a tensão evidenciada na educação entre docentes e tecnologias, a partir de uma pesquisa feita por meio da formação docente. A pesquisa é de natureza exploratória e envolve análise de natureza qualitativa, onde a metodologia utilizada para o desenvolvimento foi a pesquisa-formação multirreferencial, que partiu da seguinte problemática: Como se constitui a reconstrução de sentidos na relação entre tecnologias digitais e educação para os docentes da rede municipal de Canoas/RS? Para desenvolver o estudo foi realizado um curso de formação docente (nível extensão acadêmica) ofertado na modalidade b-learning (encontros presenciais e on-line) para os professores da rede municipal do ensino básica. Nessa investigação, foi possível evidenciar que a reconstrução de sentidos se dá na capacidade dos seres humanos em produzir significados, e isso se revela em meio às interações que emergiram durante o curso.
\end{abstract}

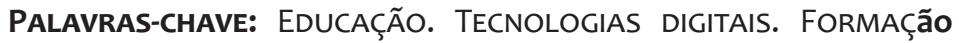
docente. RECONSTRUÇÃO DE SENTIDOS.

ABSTRACT This paper discourses about the tension between teachers and technologies evidenced by a research made during a teacher training course. The research is exploratory with qualitative analysis and a multi referential training-research methodology and started from the following question: How does the reconstruction of meanings related to digital technologies and education is made in the context of the teachers of Canoas city in Rio Grande do Sul? In order to make the study, an academic extension teacher training course was developed and applied to the teachers of basic education in the b-learning modality (presential and online meetings). In this research it is possible to evidence that the reconstruction of meanings happens in the human's ability of make meanings and this can be seen in the interactions that happened during the course.

KEY-WORDS: EdUCATION. DIGITAL TECHNOLOGIES. TEACHER TRAINING. RECONSTRUCTION OF MEANINGS.

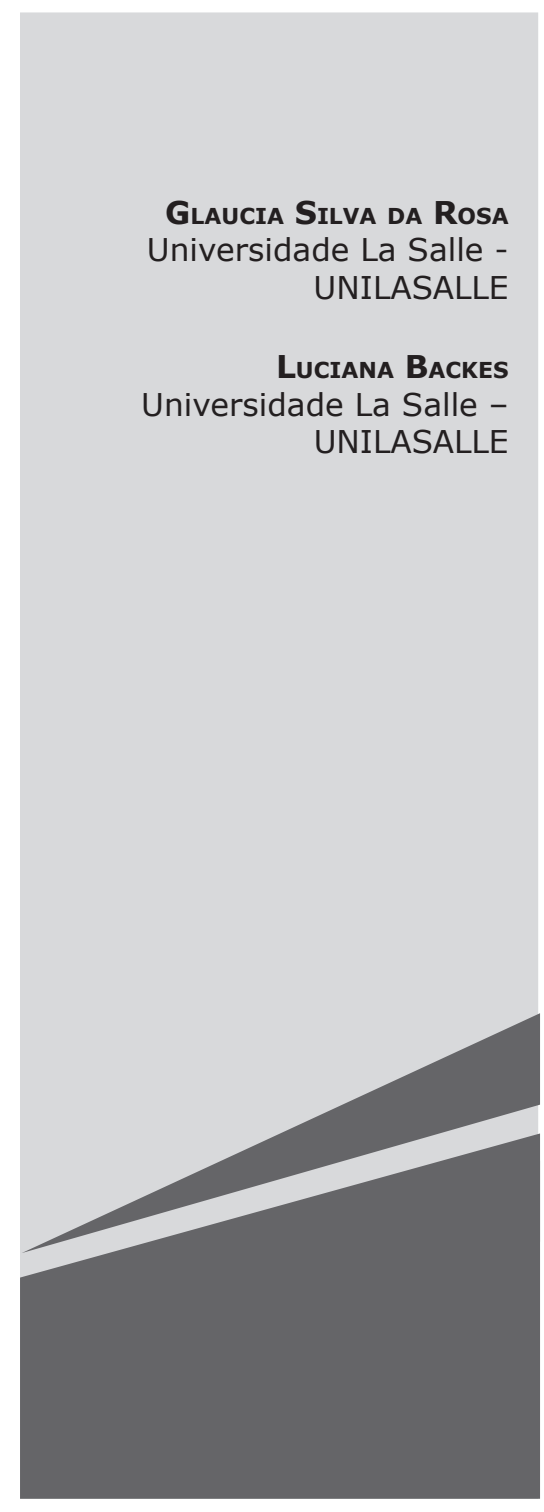


RESUMEN El artículo refleja sobre la tensión evidenciada en la educación entre docentes y tecnologías, a partir de una investigación realizada por medio de la formación docente. La investigación es de naturaleza exploratoria y involucra análisis de naturaleza cualitativa, donde la metodología utilizada para el desarrollo fue la investigación-formación multirreferencial, que partió de la siguiente problemática: ¿Cómo se constituye la reconstrucción de sentidos en la relación entre tecnologías digitales y educación para los docentes de la educación de la red municipal de Canoas/RS? Para desarrollar el estudio se realizó un curso de formación docente (nivel extensión académica) ofrecido en la modalidad b-learning (encuentros presenciales y online) para los profesores de la red municipal de enseñanza básica. En esa investigación fue posible evidenciar que la reconstrucción de sentidos se da en la capacidad de los seres humanos en producir significados, y eso se revela en medio de las interacciones que emergieron durante el curso.

Palabras Clave: Educación. TECNOLOGías digitAles. Formación DOCENTE. RECONSTRUCCIÓN DE SENTIDOS.

\section{INTRODUÇ̃̃o}

$\mathrm{N}$ os últimos anos, ouvimos falar muito, entre os diversos temas da educação, sobre: as questões das políticas educacionais; o papel docente; a importância da formação docente seja ela no âmbito da formação inicial ou continuada; os desafios do século XXI enfrentados pelos docentes e as tensões vivenciadas por eles diante desses desafios. No entanto, observamos também que, apesar de termos muitas pesquisas e o incentivo das políticas públicas em torno da temática "educação e tecnologias digitais (TD)", ainda se tem, por parte dos docentes e da escola, muito receio, medo e resistência na sua utilização em sala de aula.

Atualmente, vivemos um momento onde a expansão do consumo de computadores e dispositivos móveis supera a venda de produtos como carros e eletrodomésticos, segundo dados do Instituto Brasileiro de Geografia e Estatística - IBGE (2011), no detalhamento apresentado nos dados de 2016, a venda de dispositivos móveis supera a venda dos computadores. O cotidiano de homens e mulheres está cada vez mais com-

Disponível em: http://www.ibge.gov.br/homel . Acesso em: 12 abril de 2015 e 15 junho de 2017. plexo. Vivenciamos diferentes experiências, permeadas pelas tecnologias, que mostram a diversidade, o rompimento das fronteiras, a ubiquidade, a mobilidade, a emergência do global, a hipertextualidade, a contradição e a coexistência de todos os elementos, num fluxo intenso de interações.

No entanto, percebemos que a escola mantém suas práticas pedagógicas tradicionais, definida por Becker (2012) como Pedagogia Diretiva, fundamentada na epistemologia Empirista, nas quais o professor continua a desenvolver as mesmas metodologias e ações como centro do processo de aprendizagem. "O professor fala, e o aluno escuta. O professor dita, e o aluno copia. O professor decide o que fazer e, em geral, decide o mesmo de sempre, e o aluno executa" (p. 14). Assim, nas escolas evidenciamos a dificuldade em lidar com essa demanda complexa da sociedade contemporânea, desconsiderando esse contexto sócio, técnico e cultural. A geração de alunos que vivenciam o contexto educacional estabelece outras relações com os docentes, sobretudo quando a questão é a utilização das TDs na aprendizagem.

Essa geração não entende o docente como único detentor do conhecimento e procura identificar quais são seus interesses e desejos sobre o que estamos discutindo em 
aula, pois o seu viver e conviver acontecem nas redes sociais, nos jogos digitais, nos aplicativos de comunicação instantânea, entre outras possibilidades. Assim, há o acesso diversificado de informações, compartilhando a produção de conhecimento.

Não há dúvida alguma que essa geração tem uma intimidade ímpar com as TDs, mas os problemas de aprendizagem na construção do conhecimento continuam. Logo a utilização das tecnologias no cotidiano, por si só, não garantem a aprendizagem. Segundo Lévy (2010), a digitalização potencializada por essas tecnologias pode ser dada como um problema e não só como a solução para os problemas de aprendizagem. Não se trata apenas de incluir as TDs, mas de repensar as práticas pedagógicas com as TDs. Portanto, emerge a necessidade de se pensar uma formação docente que promova: a experiência, a pesquisa, a criatividade, a autonomia do professor em formação, inserido nessa contemporaneidade. Para Schwartz (2014, p. 12):

O papel dos educadores, das escolas e das práticas sociais é redefinido por sistemas de informação e comunicação cuja arquitetura responde cada vez mais aos imperativos de uma nova economia política do conhecimento adequada às moralidades pós-modernas. Tornou-se não apenas urgente, mas inevitável pensar criticamente a digitalização e, ao mesmo tempo, reconhecer o caráter complexo dos novos meios, ampliando o debate sobre o lugar do indivíduo, o sentido de sua formação e a temporalidade que se abre para a formulação de projetos com perspectivas locais e concretas.

Conforme o autor, um dos maiores desafios para os docentes da sociedade contemporânea é aceitar que é inevitável refletir criticamente a respeito da utilização das TDs na educação, compreendendo dessa maneira o caráter complexo que envolve as tecnolo- gias. Para além do exercício da reflexão sobre a utilização das TDs, é importante lembrar que o acesso e a apropriação das mesmas são fundamentais para a inserção no processo de aprendizagem. Conhecer como usar, explorar os instrumentos tecnológicos digitais pedagogicamente em suas potencialidades pode contribuir para o desenvolvimento de ações e/ou projetos concretos dentro das escolas.

Partindo desse cenário é que surge a necessidade que move este artigo, na busca de conhecer como os docentes da educação básica estão reconstruindo sentidos para as TDs por meio de um processo de formação docente. Para tanto, foi desenvolvida a dissertação de mestrado em Educação por Rosa (2016), na linha de pesquisa Culturas, Linguagens e Tecnologias na Educação, do Programa de Pós-Graduação em Educação, no contexto do grupo de pesquisa COTEDIC UNILASALLE/CNPq.

O artigo está organizado em cinco seções: a primeira seção (Introdução) contextualizou a utilização das tecnologias na formação docente; a segunda seção apresenta a metodologia usada na pesquisa que deu origem a este artigo; a terceira seção discute alguns resultados e análises da pesquisa, bem como, reflete sobre a reconstrução de sentidos docentes que participaram do curso; a quarta e última seção aborda as considerações finais.

\section{Metodologia de Pesquisa}

A pesquisa-formação multireferencial é um processo coletivo e dialógico entre os seres humanos na concisão de aprendentes e pesquisadores, pois "na pesquisa-formação todos são sujeitos, todos são potencialmente pesquisadores, ninguém é objeto. O objeto é a relação entre os autores" (SANTOS, 2014, p. 93-94). Nesse contexto, concordamos com Nóvoa (2004, p. 15):

Ninguém forma ninguém e que pertence a cada um transformar em formação os conhecimentos que adquire ou as relações que estabe- 
lece; recordam-nos a necessidade de prudência, que nos convida à modéstia, mas também a uma exigência cada vez maior na concepção dos dispositivos de formação.

A educação ocorre por meio de processos formadores que resultam na tomada de consciência da realidade, identificação de possibilidades de transformação da realidade, para a emancipação. Para Nóvoa (2004), "ligar docência e decência é trabalhar para uma pedagogia emancipadora” (p. 1-2). Dessa forma, o trabalho é realizado em conjunto entre quem ensina e quem aprende, pois quem ensina também aprende e quem aprende também ensina. Ao encontro disso é que se percebe a necessidade de pensar a formação partindo da realidade, da vivência e experiência do docente, em articulação com diferentes seres humanos. Conforme Santos (2014, p. 93), "a formação pessoal e a história de vida são fontes fundamentais na edificação dos saberes da docência".

A pesquisa-formação tem como concepção de olhar "o fenômeno do lado de dentro" e não de "fora", viver a experiência de dentro, fazendo parte dela e se constituindo em meio a ela. Dessa forma, "a pessoa é, simultaneamente, objeto e sujeito da formação" (NÓVOA, 2004, p. 15). Assim, para Rocha (2012, p. 93), "na pesquisa-formação, a intenção é que a intensidade com que se dá a experiência possa gerar uma transformação a partir do ato, mobilizando saberes e práxis para um autodesenvolvimento".

Dessa maneira, o curso de formação continuada "Construção de sentidos para as tecnologias digitais na educação" foi proposto junto ao Núcleo de Tecnologia Municipal NTM/Canoas, dentro do programa de incentivo à utilização de tecnologia educacional, vinculado à diretoria de formação pedagógica do município de Canoas/RS. Esse programa tem por objetivo "oportunizar a aquisição de equipamentos de notebook, segundo as configurações definidas, bem como, propiciar formação que capacitem os servidores para a utilização destas Tecnologias Educacionais" (SME Canoas, 2013, p. 68).
O curso de formação teve como objetivos: Discutir e possibilitar a reflexão em torno da questão da utilização das TDs em sala de aula; oferecer subsídios para práticas educativas por meio das TDs; resgatar a ação do professor na sua prática pedagógica. Partindo desses objetivos o curso visou potencializar o desenvolvimento da reconstrução de sentidos para as TDs na educação.

Esse curso teve a carga horária de cinquenta horas, sendo 25 horas presenciais e 25 horas on-line. A oferta foi por adesão dos docentes da educação básica: ensino fundamental (anos iniciais) e educação infantil e se realizou no período de abril a junho de 2015 . A ideia da oferta por adesão partiu do princípio de que os docentes que possuírem maior curiosidade pela temática iriam ter interesse pela proposta e, por conseguinte, se inscreveriam para participar do curso.

Foram disponibilizadas vinte vagas para o curso, esse número de vagas ofertadas foi fechado a partir de uma conversa entre as partes envolvidas na formação, NTM de Canoas/RS e pesquisadora, considerando o número significativo de participantes para uma coleta dos dados para pesquisa. Os vintes primeiros inscritos foram contemplados com a vaga. A inscrição ocorreu por meio do formulário eletrônico via Google.doc. ${ }^{2}$ Os participantes da pesquisa assinaram o termo de Consentimento Livre e Esclarecido, portanto, suas identidades foram preservadas por meio da utilização de nomes fictícios.

O curso foi organizado em três eixos, a fim de contemplar o hibridismo em que a sociedade contemporânea se insere: a) dimensão docente; b) dimensão escola; e c) dimensão tecnologias para educação. Esses eixos foram previamente distribuídos em oito encontros ao longo de dois meses.

Os dados coletados consistiram nas interações e nas produções dos docentes em formação, por meio das diferentes TDs. Na apresentação dos dados para a análise, os nomes utilizados são fictícios, com a intenção de preservar a identidade dos participantes.

\footnotetext{
Recurso do portal Google gratuito que possibilita o compartilhamento de arquivos, a criação de formulários entre outros instrumentos.
} 
A análise dos dados contemplou os seguintes conteúdos elaborados e construídos pelos participantes: três chats efetuados no Facebook, o grupo fechado no Facebook, o grupo fechado no Whatsapp, o diário de campo da pesquisadora, as representações no software Hagaquê com as histórias de vida das docentes, construção dos textos realizados no Google.doc, autoavaliação e a avaliação do curso.

Os dados foram analisados qualitativamente, a fim de refletir sobre "como se constitui a reconstrução de sentidos na relação entre TDs e educação para os docentes da rede municipal de Canoas/RS?" Para tanto foram consideradas as unidades de análise formação docente, prática pedagógica, TDs, reconstrução de sentidos, aprendizagem, interação e autoria.

Tecnologia, Cotidiano e Professores: ENTRELAÇAMENTO E RECONSTRUÇÃO DE SENTIDOS

A formação tem a intencionalidade de provocar os docentes para a compreensão de que "a aprendizagem toma-nos a todos de uma tal maneira que nos faz continuamente aprendizes, ou seja, continuamente em processo de evolução e desenvolvimento" (MASETTO, 2000, p. 138). Estamos sempre propensos a aprender algo e, por conseguinte, a construir novos sentidos para ações que emergem da sociedade em que vivemos.

Tendo em vista esse "inacabamento do ser humano" (FREIRE, 2008, p. 50), compreendemos os seres humanos em constante formação. Não estamos falando da formação destinada apenas à transferência de conhecimento, mas da formação para a construção e a reconstrução de sentidos por meio das perturbações, da curiosidade e das perguntas que emergem do viver e do conviver.

A proposta pedagógica do curso foi apresentada aos docentes no primeiro encontro com essa ideia de que "somos eternos aprendizes". A partir da exposição inicial, buscou-se estabelecer uma relação dialógica, a fim de entender que uma pesquisa com a metodologia da "pesquisa-formação multirreferencial se dá na formação dos praticantes nos seus desenvolvimentos por meio de interações complexas e nas práticas cotidianas" (SANTOS; SILVA; SANTOS, 2014, p. 57).

O curso se constituiu por meio de uma rede de interações complexas na prática cotidiana, ouvindo as docentes sobre suas expectativas e sugestões para o curso. Terminado esse movimento inicial e compreendendo a proposta do curso, o primeiro estranhamento e questionamento das docentes se referiu ao fato que não iriam aprender uma "ferramenta", mas sim reconstruir sentido para o instrumento utilizado no cotidiano. A maior expectativa das docentes era aprender a usar alguma "ferramenta" nova, por exemplo, a lousa digital recebida na maioria das escolas do município por meio de um projeto do governo federal.

As docentes relataram que geralmente os cursos de formação na área de tecnologias da informação e comunicação - TICs que participaram consistiam em mostrar e dar instruções de uso sobre determinada tecnologia, conforme o relato da docente Silvia:

Quadro 1: Registro do diário da pesquisadora.
[...] eu pensava que iríamos apren- der a mexer nas tecnologias para aplicar na sala de aula e assim construir um sentido para elas, geralmente os cursos nos ensinam como mexer em algo.

Fonte: Rosa (2016, p. 70).

Na fala de Silvia, é possível verificar a presença de uma pré-autoria por parte da docente em relação ao processo de formação docente, segundo Backes (2007, p. 124) “[...] evidenciamos uma pré-autoria quando nos autorizamos a falar sobre nossa concordância. É imprescindível ressaltar que não é uma cópia, mas uma espécie de releitura de uma obra". Assim, o relato da docente é releitura inicial feita por ela sobre o título atribuído ao curso de formação a partir das relações estabelecidas com outras experiências, em concordância.

É importante destacar que esse relato de Silvia não foi apenas encontrado no seu discurso, mas em vários discursos das do- 
centes participantes do curso no primeiro encontro que tivemos. Assim, as docentes fizeram uma espécie de "transposição" das experiências vividas a essa nova experiência. Dessa forma, a metodologia do curso causou certa perturbação nas docentes, fazendo que elas refletissem sobre a necessidade de ser autor de seus processos de aprendizagem, de modo diferente das experiências anteriores. No segundo encontro via chat do facebook a docente Dulce trouxe algumas colocações ao grupo, a fim de superar a perturbação inicial:

Quadro 2: Registro no chat da docente Dulce.

Bem, é preciso uma mudança de sentido, de estar pensando e caminhando para uma formação diferente do que estamos acostumadas, onde podemos construir as nossas aprendizagens a partir de nossas experiências. Acho que o curso veio para me possibilitar isso. Fonte: Rosa (2016, p. 71).

Figura 1: DIÁLOGO NO FACEBOOK.

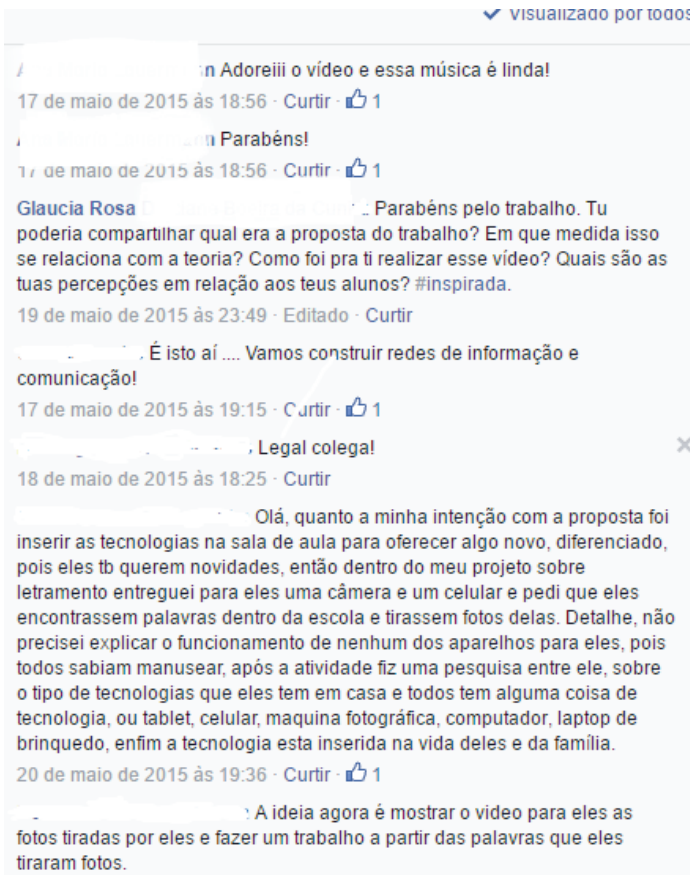

Fonte: Imagem capturada por Rosa (2016, p. 72).
A docente Dulce mostra sua percepção sobre como podemos superar a perturbação acerca da proposta do curso ao levantar aspectos como: mudança de sentido, o pensar e a construção da aprendizagem. Quando ela apresenta esse entendimento a respeito da formação, é possível perceber uma alteração de sentidos que ela começa a construir sobre a formação docente e o processo de aprendizagem.

No desenvolvimento do curso, Dulce, por meio de suas ações, foi reconstruindo seus sentidos para a utilização das tecnologias em sua prática pedagógica, como se pode observar no excerto a seguir:

A Figura 1 apresenta os extratos dos comentários das docentes sobre a postagem de um vídeo que Dulce tinha feito de sua turma. A proposta da elaboração de um vídeo aconteceu no terceiro encontro onde as docentes deveriam fazer um vídeo acerca das características do paradigma educacional emergente, a ideia era utilizar o Movie Maker para a criação do mesmo. Porém, a docente em seu
- Adorei fazer o video, achei que eles(alunos) se sairão muito bem, organizados, souberam dividir os dispositivos que eram apenas dois e ajudaram aqueles que não conseguiam enquadrar ou mesmo entender o que tinham que fazer. Eles adoraram e estão pedindo de novo, já estou pensando em novas possibilidades. Quanto a meus alunos, querem mais, conhecer mais e mexer mais e se depender de mim vou tentar propiciar isso a eles, pois penso que as tecnologias estão ai e vou aproveitar o máximo delas com eles, claro que sempre dentro de uma proposta pedagógica, por enquanto, mais para frente quero trazer os jogos para então e sempre aprender brim

20 de maio de 2015 às 19:58 - Curtir - 11

perde as vezes digitando. kkkkk

Continuando... aprender brincando. Prof. tb se

20 de maio de 2015 às 19:59 - Curtir - @2

a Teorizando um pouco trago um trecho de um texto que II para fazer nossa atividade dos qrcode que vem de encontro com o que eu penso. É um texto que foi publicado em uma revista, como não sei como se faz uma citação no face vou colocar o trecho e abaixo as

informações da revista. "Ainda trazendo a Educação infantil para o mundo contemporâneo ressaltamos que o uso das novas tecnologias deve considerar que essas crianças apesar da pouca idade já estão expostas a essas novas tecnologias e como tal necessitam dominá-las para interagir em seu meio social e a escola não pode ficar a margem desse processo."

Revista Pandora Brasil - Número 34. Setembro de 2011 - ISSN 2175-3318.

Alzeni Ferreira Lopes / Édina Maria Batista Rangel dos Santos Paula Joelma Soares Ferreira / Pollyana Valéria Gomes Brito.O desafio do uso das TIC na educação infantil, p. 170-184.

20 de maio de 2015 às 21:41 - Editado - Curtir - 131

Glaucia Rosa a, parabéns pelo video. Gostei bastante em ver que u incluiu o uso da tecnologia aliada ao teu planejamento e no contexto do projeto que a turma está desenvolvendo. Confesso que também me emocionei ao assistir teu video, pois, p... Ver mais 23 de maio de 2015 às 01:27 - Curtir 
processo de autonomia foi capaz de modificar a maneira de exibir o vídeo, identificando assim o que é significativo em seu viver. O mesmo pode ser evidenciado em relação à autoria, pois realizou uma produção diferente do que havia sido solicitado no curso de formação, ao elaborar esse vídeo a partir de uma atividade prática em sua sala de aula em conjunto com seus alunos.

Quadro 3: Relato da docente Dulce na autoavaliação.

As tecnologias estão aí, no nosso meio, nossos filhos e alunos, eles nascem nesse mundo digital e vivem isso desde o parto, mas a maioria filma seu parto, tira milhares de fotos desde que eles nascem. Então como não querer trazer isso para sala de aula, como não aprender a usufruir destas aprendizagens que eles e as tecnologias podem nos propiciar, vamos em frente, nos atirar nesse mundo virtual de cabeça. Romper com o paradigma.

$[\ldots]$

Nesse sentido é que levei as tecnologias que eu dispunha particularmente, pois a escola não oferece esse tipo de material para as crianças poderem manusear que é o que eu queria fazer e fiz com meus alunos da educação infantil. Máquina Fotográfica (manuseio das crianças), Celular (manuseio das crianças), NotBook com jogos baixados da internet (manuseio com a minha ajuda) para inovar na minha prática.

Fonte: Rosa (2016, p. 73).

Identificamos que Dulce representou sua percepção sobre o paradigma educacional estabelecendo relação com o seu viver cotidiano, mostrando isso por meio da realização de uma prática pedagógica. Parafraseando Maturana e Varela (2001), observa-se que viver é conhecer, e conhecer é viver, o que vem a resultar na reconstrução de sentidos e também em um novo conhecimento.

Além disso, Dulce mostrou uma autoria criadora, que é definida por Backes (2007, p. 163) como "produção da diferença, houve deslocamento, inversão, modificação das representações, criando uma novidade [...]”. Essa autoria está atrelada à sua autonomia que a docente teve em fazer uma proposta diferenciada, dessa forma é possível notar que o ser vivo nasce em sua propriedade com uma autonomia intrínseca, ou seja, já viemos ao mundo autônomos e distintos uns dos outros (MATURANA; VARELA, 2001). Porém, para Backes (2007) essa autonomia pode ser tolhida ou ampliada conforme a ontogenia do ser vivo.

Nesse contexto, evidenciamos também uma situação de autoria transformadora, ${ }^{3}$ a docente Sílvia postou no Facebook a atividade realizada com o software Hagaquê em suaprática pedagógica, junto a um de seus alunos na sala de recursos. Como podemos visualizar na Figura 2.

\footnotetext{
3 A autoria transformadora é compreendida em Backes (2007, p. 125) como “[...] a ação que transcende uma ação já legitimada".
} 
Figura 2: Postagem da docente no grupo do facebook.

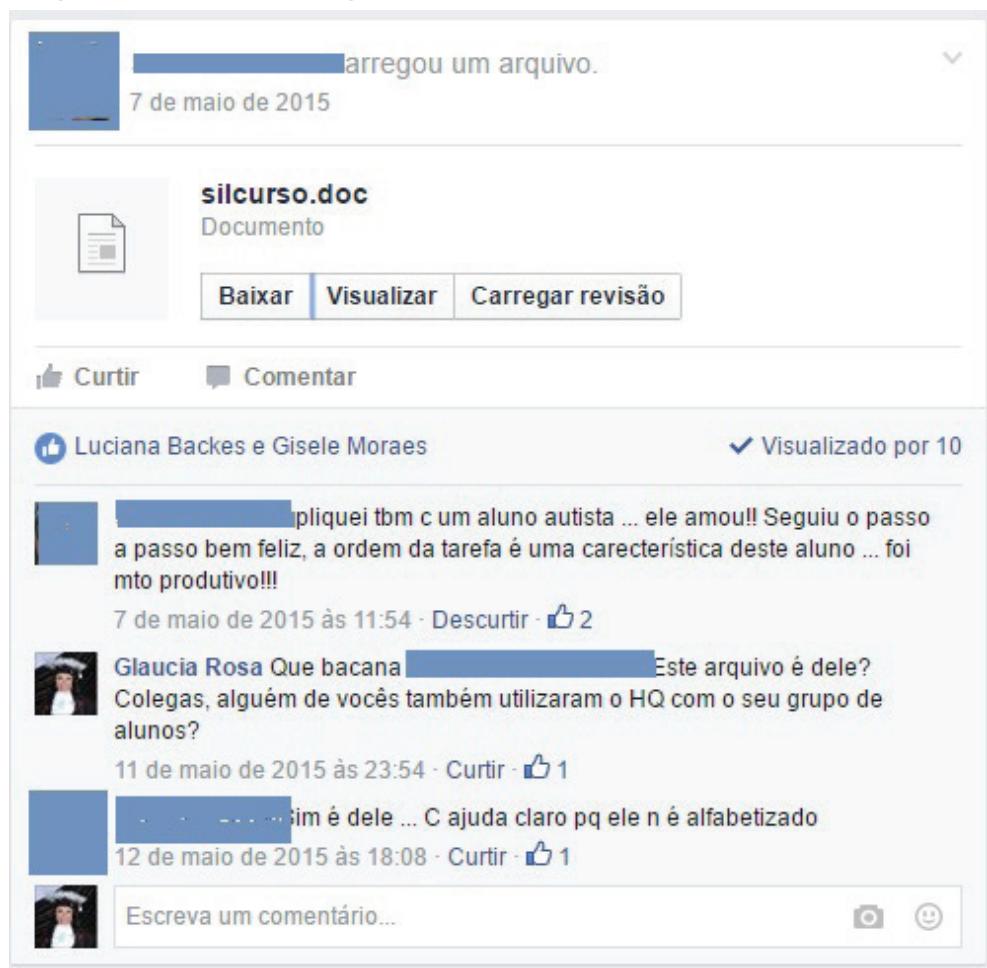

Fonte: Recorte realizado por Rosa (2016, p. 74).

A atividade proposta pela docente ao aluno consistiu na elaboração de uma história sobre os seus animais favoritos (Figura 3), a fim de proporcionar uma atividade em que a escrita tem uma função social (contar história para os outros), além de desenvolver as hipóteses a respeito do sistema da língua escrita (como se escreve). A seguir, a atividade realizada pelo aluno.

Figura 3: Aluno do $3^{\circ}$. ano (14 anos, multirrepetente) - Sala de Recursos.

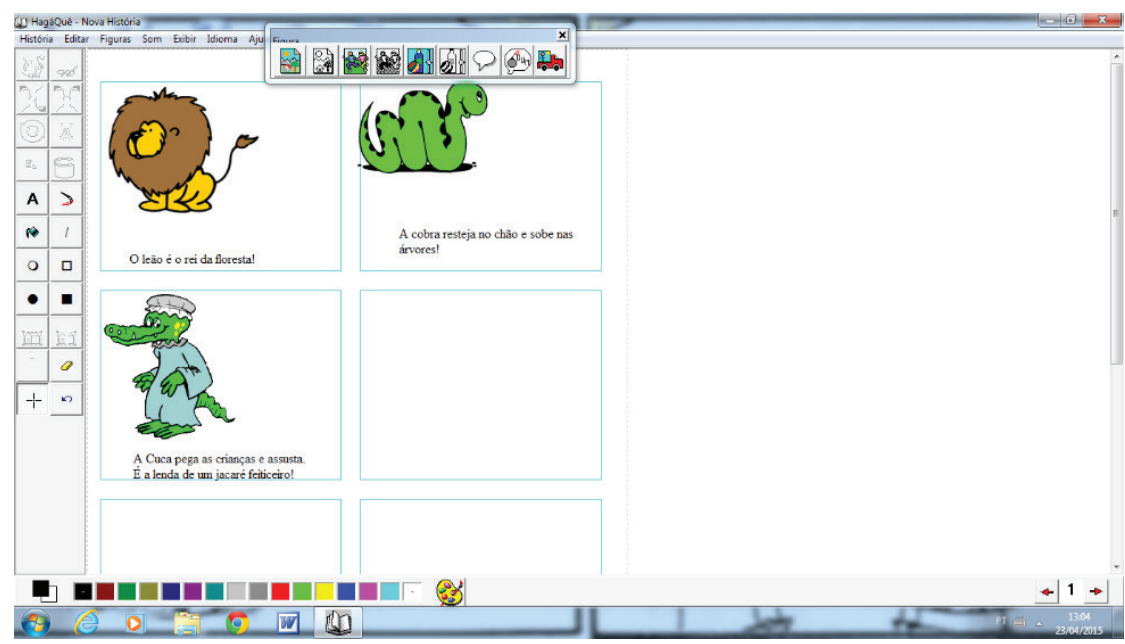

Fonte: Imagem disponibilizada pela docente Silvia, conforme Rosa (2016, p. 76). 
Então, nota-se de uma maneira singular que Silvia, após utilizar o software num dos encontros do curso de formação, reconstruiu o sentido para essa TD, por meio da utilização dessa tecnologia em sua prática docente. Nesse extrato, também é possível observar o processo de autopoiese da docente Silvia que, segundo Maturana e Varela (2001), é definida como uma ação e reflexão do ser vivo. Isso nos permite ver que o fazer acontece na autoprodução da ação e que a autoprodução do conhecimento se dá na compreensão.

A docente nessa prática mostrou sua capacidade de autoprodução na ação e na reflexão, pois ela constituiu um significado para a sua prática pedagógica. Ao utilizar o Hagaquê no curso de formação a docente articulou as características do software com o seu viver na prática pedagógica, ressignificando o sentido e potencializando a utilização dessas TDs. Diante disso, posicionou-se de maneira a levar o conhecimento para a sua prática pedagógica, trazendo a possibilidade de aprendizagem para esse aluno.

Já a docente Rosimere teve um processo diferente no que se refere ao desenvolvimento da autonomia e da autoria na reconstrução de sentido para as tecnologias proposto pelo curso. Inicialmente, ela apresentou insegurança em relação a utilizar as TDs, e essa insegurança em explorar os instrumentos tecnológicos continuou no decorrer do curso. Conforme ela relata:

Quadro 4: Relato da docente Rosimere no chat do facebook de 23/04/2015.

Eu vim ao Unilasalle, pois não iria conseguir sem a Glaucia por perto. Mexi essa semana um pouco mais no computador, mas sempre que tenho dúvida peço ajuda pra minha sobrinha.

Fonte: Recorte realizado por Rosa (2016, p. 76).

Contudo, em sua autoavaliação no final do curso, ela apresentou um elemento surpresa em seu discurso, que vinha sempre ao encontro de ter muita dificuldade, insegurança, e que não se sentia preparada para usar as TDs em sua prática pedagógica. O relato a seguir mostra que a participação no curso auxiliou na superação desse receio em relação à utilização das tecnologias.

Quadro 5: Relato da docente Rosimere em sua autoavalição.

Muitas, senão todas, as TDs trabalhadas no curso eram desconhecidas pra mim e, infelizmente nada trabalhadas em minhas turmas. Confesso que me sentia insegura para oferecer aos alunos. O curso me proporcionou uma reflexão da minha prática e sobre mim nesta era digital, pois como a professora Glaucia perguntou quem de vocês não mexe com tecnologia hoje? Me dei por conta que eu já mexo em algumas ferramentas e fiquei me perguntando por que não incluir e oferecê-las aos alunos, qualificando o trabalho escolar. Gostei de vivenciar isso, descobri muitas coisas e aprendi muito com as minhas colegas.

[...] Comecei a levar meus alunos ao Labin sozinha. Fiz um jornal com eles no Word, apesar de ser pouco ainda já é um inicio. Eles estão adorando fazer o jornal e me ajudam muito na exploração das ferramentas do word, mas aos poucos estou vencendo minha insegurança.

Fonte: Recorte feito por Rosa (2016, p. 76). 
Esse relato trazido por Rosimere mostra que a partir das perturbações vivenciadas no curso, ela se autoproduziu. Ela buscou identificar no seu cotidiano as "ferramentas" que utilizava, e assim, inseri-las na sua prática pedagógica, como o Word. Ou seja, ela reconstruiu o sentido das tecnologias em sua prática docente e é, nesse momento, que se observa a sua autoprodução, pois em congruência com o seu meio, compreendeu as aprendizagens vivenciadas no curso de formação e se posicionou diante desse conhecimento, construindo uma proposta pedagógica aos seus alunos.

No extrato a seguir verifica-se a percepção da aprendizagem imbricada à interação, pois a docente relata que aprendeu muito nas trocas que estabeleceu com as demais docentes. Na participação da docente, evidenciamos que "a vida é um processo de conhecimento, os seres vivos constroem esses conhecimentos não a partir de uma atitude passiva e sim pela interação" (MATURANA; VARELA, 2001, p. 1).

Quadro 6: Extrato de uma conversa no chat do Facebook em 23/04/2015.

$[\ldots]$ Glaucia Rosa
Gostaram dos textos?

\section{Rosimere}

Realmente são textos pra refletirmos sobre nosso trabalho.

\section{Eliana}

o que li é bem como a colega falou uma reflexão, me vi no texto

vim de uma criação onde não se podia mexer em nada...

\section{Marta}

Eu também me encontrei no texto Eliana na parte que fala de que não pode mexer para não estragar

\section{Rosimere}

Eu também me identifiquei no texto e gostei muito do paralelo "geração não" mexe que estraga e geração do mexe para ver como funciona.

\section{Dulce}

Sinto que é exatamente isso tem acontecido, somos os professores do não mexe dando aula para uma geração do "mexe". E isso precisa mudar!

Fonte: Recorte feito por Rosa (2016, p. 77).

Nesse diálogo percebemos que as docentes identificaram o seu viver e conviver no texto que abordava a questão da geração do "não mexe que estraga", no entanto, para além da identificação, as docentes percebem a necessidade de mudança de pensamento sobre as TDs. Assim, a interação aconteceu na medida em que houve a identificação, articulando o conhecimento do texto com o cotidiano, a perturbação, identificando aspectos indesejados e a superação, constatando a necessidade de reconstrução da sua história a partir das vivências em cada encontro.

Destaca-se a importância da perturbação que a leitura instigou nas docentes e a evidência da autoria transformadora representada nas falas das docentes, Dulce e Rosimere, em que elas estabelecem relação com o conhecimento construído (suas histórias) com aquilo que lhes é novo.

Então, consideramos que houve o desenvolvimento da autonomia por meio das interações e compartilhamentos estabelecidos ao longo do curso, além de evidenciar a configuração do espaço para o diálogo, como podemos observar no extrato a seguir: 
Quadro 7: Diálogo no chat do Facebook em 06/05/2015.

Gessilda: Eu já uso o whatsapp com meus alunos.

Marta: Que legal, mas como é você usa?

Gessilda: Eu uso como um grupo de apoio, eu criei um grupo para cada turma e lá eles conversam e trocam idéias sobre a matéria e trabalhos com a minha participação.

Dulce: Que legal, mas não ruim pra ti? Pois eles não mandam mensagens fora do horário de trabalho?

Gessilda: Temos algumas combinações em relação a isso, temos combinações também sobre o que vamos colocar no grupo, pois não pode ter brigas dentro do grupo eles tem que se respeitar.

Dulce: Muito legal, isso prova que dá para usar as tecnologias com os nosso alunos. E é como o texto diz que o professor tem que ter o papel de um mediador diante das tecnologias.

$[\ldots]$

Marta: Gostei da idéia, parabéns pelo trabalho, só não sei se eu estou pronta para alguma coisa parecida com meus alunos.

Fonte: Recorte feito por Rosa (2016, p. 78).

Nesse diálogo, evidenciamos as docentes interagindo em uma conversa sobre o uso do Whatsapp. A docente Gessilda, ao relatar o uso do "whats", perturbou algumas docentes que questionaram sobre como era feito esse uso. Além disso, nesse extrato podemos observar a legitimação que é atribuída a Gessilda como alguém com quem se pode aprender, pois as demais docentes aprovaram a prática pedagógica relatada. Nesse sentido, percebemos que "o aprendizado autônomo pressupõe flexibilidade, plasticidade, facilidade para mudar valores, para promover diálogos e potencializar habilidades de comunicação no que se refere à cooperação" (MORAES, 1997, p. 224).

A cooperação é outro aspecto relevante para a discussão sobre a reconstrução de sentidos, pois as docentes foram interagindo e cooperando entre si, contribuindo para a reconstrução de novas práticas. Essa interação e cooperação em alguns momentos aconteceu sem a intervenção da pesquisadora, como podemos verificar na imagem a seguir, onde as alunas criaram um espaço de chat no Facebook para elas se comunicarem em relação às atividades propostas no curso e dúvidas sobre as TDs.
Figura 4: Grupo para comunicação sobre as atividades.

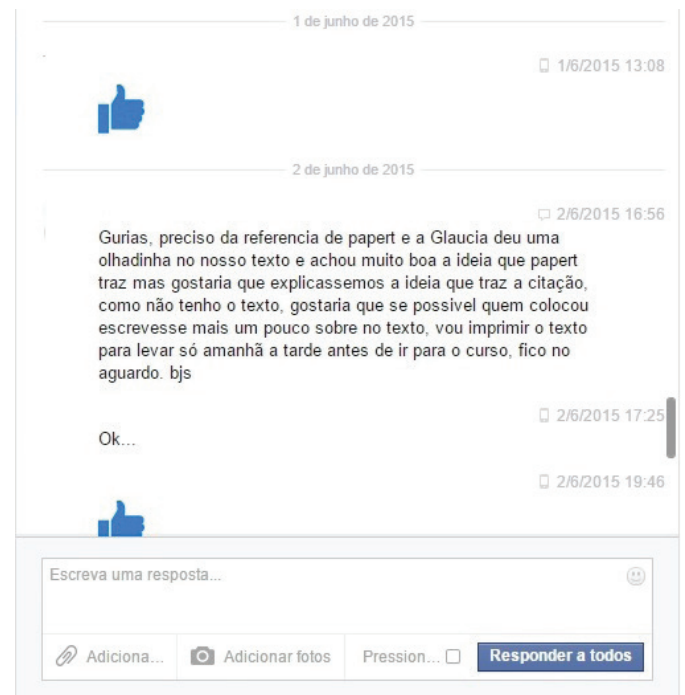

Fonte: Captura realizada por Rosa (2016, p. 79).

O relato apresentado na Figura 4 mostra o espaço de convivência configurado pelas docentes para se comunicar dentro dos pequenos grupos em que estavam elaborando um texto para o curso. Esse espaço foi configurado na convivência entre as participantes para 
trabalhar e trocar ideias sobre as atividades. Assim, as docentes tiveram autonomia para identificar alternativas significativas para as suas ações (criar o espaço) e construírem esse espaço da maneira que lhes foi conveniente, para a interação e cooperação no conviver.

Observou-se que, quando se faz ciência com a prática social cotidiana, é possível reconstruir sentidos e construir novos conhecimentos por meio das vivências e das reflexões. Portanto, percebemos na interação, no desenvolvimento da autonomia e da autoria e na aprendizagem, que ocorre a reconstrução de sentido, de cada docente de uma forma particular.

Porém, ao final do curso, as docentes perceberam que somos e seremos sempre se- res inacabados, por isso estaremos sempre em processo de aprendizagem, de construção e reconstrução de sentidos no viver e conviver. Conforme Masetto (2000, p. 140), "essa concepção de aprendizagem torna-nos a todos de uma tal maneira que nos faz continuamente aprendizes, ou seja, continuamente em processo de evolução e desenvolvimento".

Por fim, foi por meio das evidências, percebidas pela pesquisadora com as docentes no decorrer do curso, que se observou que a reconstrução de sentido só se caracteriza na medida em que as docentes em formação reconstroem suas práticas pedagógicas. Como relata a docente Camila em relação à prática realizada com o uso da lousa digital no próprio curso:

Quadro 8: Relato extraído da autoavaliação da docente Camila.

Eu particularmente, apesar de já ter algum conhecimento da lousa, fiz várias oficinas, nunca é tinha sido desafiada a mexer sozinha na lousa e foi muito legal fui mexendo e vendo se dava certo com as colegas. Adorei a experiência, acho que esse é foi um diferencial da formação e que precisamos ter esse tipo de vivência, pois isso é formação, é dar sentido as coisas. Isso, também me motivou a chegar na escola e dar um basta e querer usar a lousa. [...] Fiz uma experiência com os alunos e foi bem legal, sei que este é o começo mas é minha forma de mudar o final do que eu vinha fazendo nos meus 20 anos de docência.

Fonte: Recorte feito por Rosa (2016, p. 80).

Esse encontro, que embasou o relato da docente Camila, ocorreu quando as docentes foram recebidas no laboratório de informática. Elas se organizaram em círculo e no centro desse círculo tinha uma caixa com a lousa digital e uma placa que dizia "não mexer" com o "não" riscado. Ao se depararem com aquela caixa, logo perguntaram o que era para fazer e a pesquisadora lhes informou que era para fazer o que elas desejassem com a caixa. Inicialmente, ficaram se olhando e depois começaram a explorar.

Observando o relato apresentado pela docente Camila, evidencia-se que a prática pedagógica desenvolvida por meio da metodologia de pesquisa-formação multirreferencial, contribuiu para a ação da reconstrução de sentidos. Pois é por meio da pluralidade, que os seres humanos e objetos vão reconstruindo e reinventando seus cotidianos. Conforme Santos (2011, p. 8), "a perspectiva de aprendizagem a partir de uma multiplicidade de referenciais; são todos os espaços nos quais os seres humanos ensinam e aprendem com ou sem mediações formais ou centradas na lógica moderna das instituições de ensino".

Assim, ao final desse processo compreende-se que a reconstrução de sentidos ocorreu no momento em que as docentes agiam como seres autônomos, autores e dinâmicos, construindo relações dialógicas entre a aprendizagem/conhecimento vivenciada no curso e em congruência com o meio em que vivem. 


\section{CONSIDERAÇÕES FINAIS}

Nota-se dessa forma que o processo de reconstrução de sentido desse grupo aconteceu na medida em que as docentes em seus processos de emancipação compreenderam que é fundamental compreender "por que" estão utilizando as TDs no desenvolvimento de suas práticas pedagógicas, assim, faz que aja coerência e congruência na utilização.

Dessa maneira, as docentes foram reconstruindo sentido para a utilização das TDs por meio da autonomia, autoria e interação no cotidiano, que aconteceu a partir da legitimação do processo, assim, as docentes participantes começaram a usar as TDs na prática pedagógica. A partir deste contexto, evidenciamos como elas utilizaram as TDs em suas práticas e como elas foram reconstruindo um sentido para a utilização das TDs.

As docentes, inicialmente, começaram a utilizar as TDs trabalhadas no curso em suas práticas pedagógicas em atividades se- melhantes às propostas no curso, conforme Maturana e Varela (2001) o viver é conhecer. Outras docentes foram além, procurando conhecer outros instrumentos tecnológicos, segundo Maturana e Varela (2001) na perspectiva do conhecer é viver.

Portanto, as docentes foram percebendo por meio de viver, conviver e conhecer que as tecnologias não devem ser o "fim", mas o "meio", ou seja, a finalidade não deve ser aprender a mexer em um instrumento tecnológico ou ter um momento de entretenimento em sala de aula, mas o meio que possibilita a exploração de novos conhecimentos. Desse modo, as tecnologias podem contribuir para os processos educativos na proporção em que elas estabelecem relações de interação e cooperação entre os seres humanos envolvidos na prática por intermédio das tecnologias.

E, por fim, observa-se que estamos sempre num constante movimento, articulando novas aprendizagens e novos conhecimentos, e isso torna seres inacabados numa infinita reconstrução de sentidos.

\section{REFERÊNCIAS}

ALMEIDA, M. E. B.; PRADO, M. E. B. B. Integração tecnológica, linguagem e representação. Disponível em: <http://www.tvebrasil.com.br/salto>. Acesso em: 3 fev. 2015.

BACKES, L. Mundos virtuais na formação do educador: uma investigação sobre os processos de autonomia e de autoria, 186s. Dissertação (Mestrado em Educação) - Universidade do Vale do Rio dos Sinos, São Leopoldo, 2007.

. A configuração do espaço de convivência digital virtual: a cultura emergente no processo de formação do educador, 362s. Tese (Doutorado em Educação) -Universidade do Vale do Rio dos Sinos, São Leopoldo, 2011.

BECKER, F. Educação e Construção do Conhecimento, 2. ed. Revista e Ampliada. Porto Alegre: Penso, 2012.

FREIRE, P. Pedagogia da autonomia: saberes necessários à prática educativa, 37. ed. São Paulo: Paz e Terra, 2008.

LÉVY, Pierre. O que é virtual? São Paulo: Editora 34, 2010.

MACHADO, J. R.; TIJIBOY, A. V. Redes Sociais Virtuais: um espaço para efetivação da aprendizagem cooperativa. Novas Tecnologias na Educação, Porto Alegre, v. 3, n. 1, p. 1-9, mai. 2005.

MASETTO, M. Mediação pedagógica e o uso das tecnologias. In: MORAN, J. M.; MASETTO, M.; BEHERNS, M. Novas tecnologias e mediação pedagógica, 12. ed. Campinas: Papirus, 2000. 
MATURANA, H. R.; VARELA, F. J. A Árvore do Conhecimento: as bases biológicas da compreensão humana. São Paulo: Pala Athenas, 2001.

MERCADO, L. P. Formação Continuada de Professores e Novas Tecnologias. Maceió: Edufal, 1999.

MORAES, M. C. O paradigma educacional emergente. São Paulo: Papirus, 2002.

NÓVOA, Antônio. Prefácio. In: JOSSO, M. C. (Org.). Experiências de vida e formação. São Paulo: Cortez, 2004.

. Currículo e Docência: a pessoa, a partilha, a prudência. In: GONÇALVES, E. P.; PEREIRA, M. Z. C.; CARVALHO, M. E. P. (Orgs.). Currículo e contemporaneidade: questões emergentes. Campinas: 2004. Disponível em: <http://repositorio.ul.pt/bitstream/10451/4816/1/8575161121_1_11. pdf >. Acesso em: 12 mai. 2015.

ROCHA, Aline Andrade Weber Nunes da. Educação e Cibercultura: narrativas de mobilidade ubíqua, 2012, 210s. Dissertação (Mestrado em Educação) - Faculdade de Educação, Universidade do Estado do Rio de Janeiro, Rio de Janeiro, 2012.

ROSA, S. G. A Reconstrução de Sentidos sobre as Tecnologias Digitais na Formação Docente, 115s. Dissertação (Mestrado em Educação) - Centro Universitário La Salle, Canoas, 2016.

SANTOS, E. O. Entrevista ao programa Salto para o Futuro. TV Brasil. Rio de Janeiro, 11 jan. 2011. Disponível em: http://tvbrasil.org.br/saltoparaofuturo/entrevista.asp?cod_Entrevista=119. Acesso em 19 jul. 2016. Pesquisa-Formação na cibercultura. Portugal: Whitebooks, 2014.

SANTOS, E. O.; SILVA, F.; SANTOS, R. Composições híbridas na pesquisa-formação multirreferencial. Revista Tempos e Espaços em Educação, v. 14, p. 53-62, set./dez., 2014.

SANTOS, R. S.; SANTOS, E. O. Professores em formação em busca dos sentidos contemporâneos. Revista Galego-Portuguesa de Psicoloxia e Educación, v. 20, p. 171-185, 2012.

SCHLEMMER, E. Formação de Professores na Modalidade Online: experiências e reflexões sobre a criação de Espaços de Convivência Digitais Virtuais ECODIs. Em Aberto, v. 23, p. 99-122, 2010.

SCHWARTZ, G. Brinco, Logo, Aprendo: Educação, videogames e moralidades pós-modernas. São Paulo: Paulus, 2014.

\section{SITES CONSULTADOS}

Instituto Brasileiro de Geografia e Estatística - IBGE (2011): http://www.ibge.gov.br/home/ Secretaria Municipal de Educação - SME Canoas. Projeto Político Pedagógico (2013): http:// www.canoas.rs.gov.br/uploads/paginadinamica/368998/cartilha_pdf.pdf

\section{SOBRE OS AUTORES}

\section{GLAUCIA SiLVA DA Rosa}

Mestre em Educação pelo Programa de Pós-Graduação em Educação da Universidade La Salle - Unilasalle. Especialista em Psicopedagogia e TICs (2015) pela Universidade Federal do Rio Grande do Sul (UFRGS).

E-mail: glauciabert@gmail.com 


\section{LUCIANA BACKES}

Doutorado em Educação pela Universidade do Vale do Rio dos Sinos e Sciences de l'Education pela Université Lumière Lyon 2. Professora titular da Universidade La Salle - Unilasalle, Programa de Pós-Graduação em Educação.

E-mail: luciana.backes@unilasalle.edu.br

Recebido em: 30 de março de 2018

Aprovado em: 20 de junho de 2018 